Itinéraires Itinéraires

Littérature, textes, cultures

2012-2 | 2012

Intime et politique

\title{
Collectif, Ils se sont tant aimés : $f(r)$ ictions politiques
}

Paris, La Cause des Livres, 2012, 156 pages

Martine Lévy

\section{CpenEdition}

Journals

Édition électronique

URL : http://journals.openedition.org/itineraires/1211

DOI : 10.4000/itineraires. 1211

ISSN : 2427-920X

Éditeur

Pléiade

\section{Édition imprimée}

Date de publication : 1 novembre 2012

Pagination : 172-174

ISBN : 978-2-336-00027-5

ISSN : 2100-1340

Référence électronique

Martine Lévy, "Collectif, Ils se sont tant aimés : f(r)ictions politiques », Itinéraires [En ligne], 2012-2 | 2012, mis en ligne le 01 novembre 2012, consulté le 22 septembre 2020. URL : http://

journals.openedition.org/itineraires/1211 ; DOI : https://doi.org/10.4000/itineraires.1211

Ce document a été généré automatiquement le 22 septembre 2020.

\section{(2) $\oplus \Theta \Theta$}

Itinéraires est mis à disposition selon les termes de la licence Creative Commons Attribution - Pas d'Utilisation Commerciale - Pas de Modification 4.0 International. 


\title{
Collectif, Ils se sont tant aimés : $f(r)$ ictions politiques
}

Paris, La Cause des Livres, 2012, 156 pages

\author{
Martine Lévy
}

\section{RÉFÉRENCE}

Collectif, Ils se sont tant aimés : $f(r)$ ictions politiques, Paris, La Cause des Livres, 2012, 156 pages.

1 Le 19 juillet 2011, je lançais sur notre site web http://www.lacausedeslivres.com un appel :

Appel du 19 juillet : textes littéraires wanted. Nous attendons vos textes de fiction et d'autofiction autour de la politique, du pouvoir...

L'actualité politique est riche et reflète l'âme humaine. À La Cause des Livres, nous aimons la politique et la littérature. D'où l'idée de lier les deux, pour une création originale. Nous allons publier début 2012 un recueil composé de textes courts que vous aurez écrits autour de la politique : autour de l'envie du pouvoir, des alliances, des discours, de la séduction, des rivalités, etc. (par exemple, une histoire d'enfants qui auraient des parents qui voudraient tous les 2 devenir présidents de la République !).

Ni pamphlet, ni thèse de sciences politiques, nous nous attacherons au scénario, à la psychologie des personnages, à l'écriture. Nous attendons vos autofictions et fictions politiques. Titre général du recueil : Ils se sont tant aimés.

Longueur de votre texte : maximum 100000 signes. Pas de minimum. Pour quand? Le 20 octobre 2011 au plus tard...

2 Éditrice et citoyenne, j'ai eu le désir, durant l'automne 2011 de participer à l'effervescence politique qui régnait en France. Mes goûts personnels penchaient plutôt vers la littérature autobiographique. Comme l'a écrit Helen Epstein ${ }^{1}$, «tandis qu'une partie de moi lisait pour me perdre, une autre lisait pour apprendre comment vivent les autres ». 
Mais parfois, la réalité dépasse la fiction. Fiction et réalité dans la littérature, voici un axe qui intéresse les lecteurs d'autobiographie. Vaste sujet...

3 L'un des déclencheurs de cet appel fut la déclaration d'intention de François Hollande de se présenter à l'élection présidentielle de mai 2012. Son ex-compagne, Ségolène Royal, était aussi candidate à la présidence, pour la seconde fois. J'ai pensé à leurs enfants, enfants dont les deux parents briguaient la fonction suprême, ce qui était, je crois, une situation inédite. Cette phrase m'est alors venue : « Ils se sont tant aimés... ». Puis: "Que ferais-je si mes deux parents voulaient devenir président de la République? » Là, le désir de fiction s'est fait sentir... Cette situation m’a paru très romanesque. J'ai proposé le sujet à quelques écrivains et bizarrement, cela ne les a pas intéressés. M'est alors venue - dans la nuit du 18 au 19 juillet précisément - l'idée de lancer par notre site un appel à fictions politiques. Ce fut très étrange, inédit, cette idée s'est véritablement imposée dans un rêve éveillé. Le lendemain, je lançais cet appel dans notre newsletter sur Internet. Je me sentais juste dans mon rôle d'éditrice, de citoyenne qui offre à d'autres citoyens la possibilité d'écrire et d'être édités dans un recueil collectif.

4 Je suggérais donc "enfants de", mais sans fermer la porte à d'autres sujets. Je suggérais un titre. Deux axes me guidaient: d'une part, je ne voulais ni pamphlets, ni thèses, ni cynisme, ni dérision. Je voulais qu'il y ait à la fois de la littérature et de la citoyenneté, des histoires d'humains. La politique est quelque chose de précieux, les mots « démocratie » et « liberté » sont deux mots importants dans ma vie personnelle. Dans ma famille, la politique comptait. L'engagement, l'intérêt pour l'autre, le service public - mes parents étaient médecins - étaient des valeurs premières. D'autre part, je voulais qu'on nous raconte des histoires. Si on lit, si on écoute, si on s'intéresse à la politique, la réalité dépasse la fiction. Il ne restait qu'à attendre que les textes arrivent. J'avoue que je ne savais pas du tout si cette aventure éditoriale aboutirait.

5 Cet appel a été relayé puisque nous ne connaissions pas la majorité des auteurs des textes reçus. Nous avons reçu une centaine de textes en quatre mois. Nous avons lu tous les textes, le comité de lecture s'est réuni plusieurs fois. Nous avions des délais très courts puisque je souhaitais que le livre paraisse au cours du premier trimestre 2012, avant l'élection présidentielle. Au final, onze textes ont été retenus.

Nous avons perçu un grand besoin de fiction, et ce qui m'a frappée en lisant ces textes, c'est que la politique est une véritable comédie humaine au sens balzacien du terme. Les ressorts qui mènent les gens à aimer le pouvoir, à militer, à se révolter, à se souvenir, sont très intimes. On le sent dans une nouvelle comme L'apprentissage: un homme décide de devenir maire, il se bat comme un fou pour l'être, il le devient, puis un événement inattendu fait sombrer son désir.

7 Les onze nouvelles sont très variées, tant sur la forme que sur le fond et il y en a pour tous les goûts. Les liens entre les gens sont vraiment interrogés. Qu'est ce qui nous lie, qu'est-ce qui nous fait courir? Finalement aucune ne parle des enfants de présidents potentiels. Trois parlent des sans-papiers, de façons très différentes.

8 Pour ma part, je suis heureuse d'avoir mené à bien cette aventure éditoriale. Onze univers sont réunis dans ce livre collectif, pour une promenade dans l'air du temps. 


\section{NOTES}

1. Helen Epstein, Écrire la vie, Paris, La Cause des Livres, 2009. 